\title{
Vulval Infection, CTCAE
}

National Cancer Institute

\section{Source}

National Cancer Institute. Vulval Infection, CTCAE. NCI Thesaurus. Code C143943.

A disorder characterized by an infectious process involving the vulva. 